Published in final edited form as:

Am J Cardiol. 2012 June 1; 109(11): 1589-1593. doi:10.1016/j.amjcard.2012.01.381.

\title{
Recent Trends in Hospitalization for Acute Myocardial Infarction
}

\author{
Oliver J. Wang, MD, MHS, MBA ${ }^{a}$, Yongfei Wang, MS $^{\mathrm{b}, \mathrm{c}}$, Jersey Chen, MD, MPH $^{\mathrm{c}}$, and Harlan \\ M. Krumholz, MD, MS \\ ${ }^{a}$ Kaiser Permanente, West Los Angeles Medical Center, Los Angeles, California \\ ${ }^{b}$ Center for Outcomes Research and Evaluation, Yale-New Haven Hospital, New Haven, \\ Connecticut \\ 'Section of Cardiovascular Medicine, Department of Medicine, Yale University School of \\ Medicine, New, Haven, Connecticut \\ ${ }^{\mathrm{d}}$ Center for Outcomes Research and Evaluation, Yale-New Haven Hospital, New Haven, \\ Connecticut, Robert Wood Johnson Clinical Scholars Program, Department of Medicine; and the \\ Section of Health, Policy and Administration, School of Public Health, Yale University School of \\ Medicine, New Haven, Connecticut
}

\section{Abstract}

Rates of acute myocardial infarction (AMI) hospitalizations for elderly Medicare patients decreased during the last decade. However, trends in population rates of AMI hospitalizations for all adults by subgroups have not been described. Using data from a large, all-payer administrative database of hospitalizations, we calculated annual AMI hospitalization rates from 2001 to 2007. Trend analysis was performed across age, gender and ethnicity categories using survey regression. The overall rate decreased from 314 to 222 AMI hospitalizations per 100,000 persons from 2001 to 2007 , representing a $29.2 \%$ decline. Significant declines were observed in the AMI hospitalization rate for each group by age categories $(\mathrm{p}<0.001)$ and by gender $(\mathrm{p}<0.001)$. When stratified by ethnicity and gender, the age-adjusted AMI hospitalization rates in white men and women decreased by $30.8 \%$ and $31.4 \%$ while black men and women had significantly slower rates of decline of $13.6 \%$ and $12.6 \%$, respectively. In conclusion, while the overall rate of AMI hospitalizations decreased over the 2001 to 2007 period, the observed decline was smaller for black patients compared with white patients across all age groups studied.

\section{Keywords}

Acute myocardial infarction; hospitalization; disparities

\section{Introduction}

Recent studies have reported substantial decreases in AMI hospitalization rates in older, Medicare fee-for-service patients and in studies with data collected within a single state (15). Despite the impact of AMI on the inpatient health care system, it is not known whether

\footnotetext{
(C) 2012 Excerpta Medica, Inc. All rights reserved.

Corresponding Author and Requests for Reprints: Oliver J. Wang, ojw1997@gmail.com. Kaiser Permanente, 6041 Cadillac Avenue, West Los Angeles Medical Center, Los Angeles, CA 90034; (p) 323-857-4235, (f) 310-876-1973.

Publisher's Disclaimer: This is a PDF file of an unedited manuscript that has been accepted for publication. As a service to our customers we are providing this early version of the manuscript. The manuscript will undergo copyediting, typesetting, and review of the resulting proof before it is published in its final citable form. Please note that during the production process errors may be discovered which could affect the content, and all legal disclaimers that apply to the journal pertain.
} 
the recent trends in the Medicare fee-for-service population are generalizable to younger patients and other subgroups. While prior work has demonstrated that there may be ethnicity and gender based disparities in early mortality for myocardial infarction (6-7), it is not known whether these differences are present in AMI hospitalization trends in younger populations. Characterizing differences in AMI hospitalization rates among a larger group of patients stratified by age, gender, and ethnicity may highlight areas of relative progress and help guide decisions on optimal allocation of resources in prevention strategies. AMI hospitalization trends from a large national database may also provide hypothesis generating insights on the benefits of recent improvements in primary and secondary prevention in cardiovascular disease (8-9). The National Inpatient Sample (NIS) from the Healthcare Cost and Utilization Project (HCUP) is an all-payer administrative database of hospitalization. HCUP includes information from Medicare, Medicaid, active and retired military insurance, private insurers and the uninsured, which provides a more representative sample of patients. The NIS sample includes 41 states which accounts for approximately $94 \%$ of the US population (10). For this study, we examined recent AMI hospitalization rates during 20012007 in using an all-payer database, and compare AMI trends between age, gender and ethnicity subgroups.

\section{Methods}

The National Inpatient Sample (NIS) from the Healthcare Cost and Utilization Project (HCUP) is a longitudinal hospital inpatient database containing all discharge data from over 1,000 hospitals located in 41 states, approximating a $20 \%$ stratified sample of U.S. community hospitals. The NIS captures both incident and recurrent AMI hospitalizations. Data include discharge-level data files with both trend weights and data elements consistently defined across data years (http://www.hcup-us.ahrq.gov/db/nation/nis/nistrends.jsp). Using NIS data in HCUP from 2001-2007, we selected the following fields for analysis: age, gender, ethnicity, discharge status, length of stay, in-hospital death, principal diagnosis codes in order to identify AMI hospitalization, state of hospitalization, and the universal discharge weights which can be used to estimate the total number of events or admissions of the hospital. A hospitalization was classified as an AMI hospitalization if the primary discharge diagnosis was 410.xx, excluding 410.x2, based on International Classification of Diseases, 9th revision, clinical modification. We included only primary discharge diagnoses of AMI since non-primary diagnoses may not reflect an acute process or does not reflect the reason for admission.

2000 Census data with annual, intercensal survey adjustments were used to calculate each subgroup population of subjects at risk for AMI in order to calculate population-based overall and AMI rates. (http://www.census.gov/popest/states/). Corresponding numbers of people are calculated for the subgroups stratified by state, age groups, gender, and ethnicity in separate years from these data.

All discharges from hospitals in the HCUP-NIS from 2001-2007 were initially included $(n=55,402,296)$. We then excluded discharges with missing data on patient age, gender, length of stay, and in-hospital death $(\mathrm{n}=194,331,0.4 \%)$; discharges in which patients' age is $<18$ years old $(n=9,735,028,17.3 \%)$; discharges in which the patient discharged alive and on the same day of the admission because they were unlikely to be with acute disease $(\mathrm{n}=832,472,1.8 \%)$; and discharges in which the patient was transferred in from another hospital ( $\mathrm{n}=155,008,3.5 \%$ ), leaving a cohort of $43,272,788$ discharges. To examine the trend stratifying by ethnicity in white and black patients, we limited to the 21 states that reported ethnicity data during each year in the study and excluded discharges in which the patients' ethnicity was neither white nor black, which resulted in a study cohort of $22,713,429$ discharges. 
The AMI hospitalization rate was expressed as the number of AMI hospitalizations divided by the number of corresponding Census based persons within a given group. First we examined the distribution of AMI patients' characteristics related to age $(<45,45$ to $<55,55$ to $<65,65$ to $<75$, and $\geq 75$ years), gender (male and female), and ethnicity (white and black). Then we examined the AMI hospitalization rates stratified by subgroups of age, gender, and ethnicity. We also calculated overall hospitalization rates stratified by subgroups of age, gender and ethnicity to provide a comparison for trends observed in AMI hospitalizations. Finally, we calculated the age-adjusted AMI hospitalization rates in the subgroups determined by a combination of gender and ethnicity. Linear trend of adjusted rates over different year was calculated using Poisson regression analyses. All the rates were calculated per 100,000 persons based on population information from the Census summary data. All statistical analyses of hospitalization rates were conducted with SAS version 9.2 (SAS Institute Inc, Cary, NC).

\section{Results}

There were 2,179,509 AMI hospitalizations from 2001 to 2007 in the study sample. The overall rate decreased from 314 AMI hospitalizations per 100,000 persons to $222 \mathrm{AMI}$ hospitalizations per 100,000 persons, representing a $29.2 \%$ decline. The decline in AMI hospitalizations occurred in the setting of a $5.2 \%$ decline in the population based rate of hospitalizations in the same dataset. There was a significant decline (with relative decreases in percentages) over the study period in AMI hospitalization rate for each group by age category: <45 years of age (24.6\%), 45 to $<55$ years of age (26.7\%), 55 to $<65$ years of age (34.0\%), 65 to $<75$ years of age (34.8\%), and $\geq 75$ years (32.4\%) (Table $1, \mathrm{p}<0.001$ for each age category). Similarly, significant declines were also seen across gender and ethnicity (Table $1, \mathrm{p}<0.001$ ).

Absolute decreases in the AMI hospitalization rate were greater in older patients compared with younger patients. For example, the absolute change was 518 AMI hospitalizations per 100,000 persons for patients $>75$ years compared with 7 AMI hospitalizations per 100,000 persons for patients $<45$ years). The rate in men and women decreased 109 and 76 AMI hospitalizations per 100,000 persons and there is a significant higher percent decline in men compared with women $(\mathrm{p}<0.01)$. Additionally, white adults had a greater absolute decline compared with black adults (100 vs. 32 AMI hospitalizations per 100,000 persons), however the linear decline trends were not significant between white and black patients $(\mathrm{P}=0.2)$.

The relative decline in AMI hospitalization rates in white and in black patients was $30.8 \%$ and $13.7 \%$, respectively. While the overall decline in AMI hospitalization rates in black patients was significant over the 2001-07 period, there was an upward trend over the 200102 and 2005-07 periods.

Table 2 showed the AMI hospitalization rates stratified by gender and ethnicity in different age groups for patients from a subgroup of states reporting ethnicity data in all the years during the 2001-2007 period. In the group < 45 years of age, only white men demonstrated a significant decline in AMI hospitalization rates. White women had minimally lower rates while black men and women showed a slight increase although these changes did not reach significance. In all other age groups, every category by ethnicity and gender showed a significant decline in AMI hospitalization rates $(\mathrm{p}<0.01)$.

White men had the largest absolute decrease in AMI hospitalization rates in each age group studied. While white men had the highest AMI hospitalization rate in each age category in the first year of the study, by 2007 black men had the highest AMI hospitalization rate in four out of five age categories. The pattern of relative changes in AMI hospitalization rates 
was similar to the changes observed in absolute rates. White men or women had the largest or second largest relative decline in all age groups with significant trends. Black men and women had smaller relative declines ranging from $-0.7-28.8 \%$ but had the lowest or second lowest relative decline in all age groups with significant trends.

Age-adjusted AMI hospitalization rates over the 2001-2007 period are presented in Table 3. White men had a $30.8 \%$ relative decline while white women had a $31.4 \%$ relative decline with a year-to-year decrease in the absolute rate. Relative declines in black men and women were $13.6 \%$ and $12.6 \%$, respectively. The rates in black men were lower than in white men during the first year of the study $(\mathrm{p}=0.004)$ and were not significantly different during the last year of the study $(\mathrm{p}=0.6)$. This relative change can be explained by the greater decreases observed in the AMI hospitalization rate in white men compared with black men. In contrast, rates in black women and white women did not differ during the first year of the study $(\mathrm{p}=0.5)$ but by the last year of the study, rates in white women were significantly lower $(\mathrm{p}<0.001)$. The diverging rates over the study period between black and white women were driven primarily by the trend that white women had the second largest absolute decrease in two of the age groups studied, despite having the lowest or second lowest initial AMI hospitalization rate. While there was not a consistent year-to-year decline in black men and women, the overall trend was significant. The observed increase in black men and women over the 2005-2007 period was not significant.

\section{Discussion}

The AMI hospitalization rate for adult patients from an all-payer database has declined 29.2\% from 2001-2007. Had overall hospitalization rates remained at 2001 levels over the study period, this would have resulted in approximately 500,000 more AMI hospitalizations over the 2001-2007 period. This overall decline in AMI hospitalizations was observed across almost all age, ethnicity and gender categories studied. Excluding the youngest patients, where the incidence is relatively low, significant declines were seen across all remaining age groups. The relative declines observed for men and women were similar over the time period. This is in contrast to trends by ethnicity, where the rate of decline in blacks was smaller compared with whites.

The overall decline in AMI hospitalization rates confirms and extends other recent work in regional and Medicare fee-for-service populations (3-5) by characterizing a decline in AMI hospitalization in all adult patients across the majority of US states One explanation for this trend is that it represents a true decrease in the incidence of AMI hospitalizations. This decline could be explained through improved cardiovascular risk factor management as well as the adoption of new pharmacologic agents and treatments $(8,11,12)$. The advances in primary and secondary prevention for AMI introduced over the last decade may have resulted in progressively fewer AMI hospitalizations. An alternative explanation is that there was a broader decline in all hospitalizations without a distinctive decrease in AMI hospitalizations. This is not likely given that the decline in AMI hospitalizations occurred in the setting of a relatively smaller decrease of $0.7 \%$ in all hospitalizations during the 20012007 period. This downward trend also occurred during the increasing use of more sensitive troponin biomarker assays which have been theorized to increase the diagnosis of AMI (13).

The decline in AMI hospitalizations for black adults was less than what was observed in white adults. This smaller decline was also accompanied by year to year changes that included an increase over the last three years of the study period. While the trend in the last three years was not significant, the overall differences in the magnitude of decline could be explained by the finding that relative declines in cardiovascular risk factors are smaller in blacks adults compared with those observed in white adults (14-15). In prior work, blacks 
were shown to have higher rates of obesity and hypertension compared with whites. It is reasonable to infer that racial disparities in cardiovascular risk factors over time may have contributed to the relatively smaller decline observed in AMI hospitalizations for black adults (16). It is not clear why black men had lower AMI hospitalization rates at the beginning of the study period, but this difference diminished over time.

There implications from this study are 2-fold. First, there has been a broad decline in AMI hospitalizations across age and gender over the last several years. Assuming that the rates remained at 2001 levels, this decline represents a large reduction in the utilization of inpatient resources directed towards AMI care. If this decline is due in part to progress in primary and secondary prevention, it provides downstream feedback on the impact of advances in AMI care. Second, there is a racial disparity in the change in AMI hospitalization rates for black adults compared to white adults. Age-adjusted analysis demonstrates that while black men had a lower absolute rate at the beginning of the study period compared to white men, the rates converged over time. In contrast, black and white women began the study with similar absolute rates at the outset that diverged by the end of the study period. This apparent difference of seems to argue against the idea that the greater decreases seen in white individuals is due only to higher absolute rates of AMI hospitalization in whites compared with blacks.

Administrative data cannot, with certainty, provide information about the type of AMI or its mechanism. However, administrative data has been shown to have reasonable correlation with AMI diagnosed with clinical data (17). The changes observed in this study may be due to shifts in coding practices of AMI to other cardiovascular diagnoses. However, prior work using ICD-9 codes over similar time periods in older patients suggests that there was not a compensatory increase in related cardiovascular diagnoses to explain the overall decline in AMI hospitalization rates(3). Differences in coding ethnicity data between states or within states may have affected the trends observed. However, we included only states that reported data in each year of the study period. In addition, the number of "other" reported in state level ethnicity data decreased each year over the study period, suggesting that any increase observed over the last three years is less likely to be due to a coding shift. While the majority of HCUP states do report ethnicity level data, trends observed may not apply to the states that did not report ethnicity level data.

\section{Acknowledgments}

This study was funded in part by the Robert Wood Johnson Clinical Scholars Program and conducted in collaboration with the Yale University NHLBI Center for Cardiovascular Outcomes Research which is sponsored by the National Heart, Lung, and Blood Institute (NHLBI), study \# 1U01HL105270-01. Both are located in New Haven, CT.

\section{References}

1. DeFrances CJ, Lucas CA, Buie VC, Golosinskiy A. 2006 National Hospital Discharge Survey. Natl Health Stat Report. 2008; 30(5):1-20. [PubMed: 18841653]

2. Fang J, Alderman MH, Keenan NL, Ayala C. Acute myocardial infarction hospitalization in the United States, 1979 to 2005. Am J Med Mar. 2010; 123(3):259-266.

3. Chen J, Normand SLT, Wang Y, Drye EE, Schreiner GC, Krumholz HM. Recent declines in hospitalizations for acute myocardial infarction for medicare fee-for-service beneficiaries: Progress and continuing challenges. Circulation. 2010; 121(11):1322-1328. [PubMed: 20212281]

4. Roger VW, Gerber Y, Killian JM, Killian JM, Dunlay SM, Jaffe AS, Bell MR, Kors J, Yawn BP, Jacobsen SJ. Trends in Incidence, Severity, and Outcome of Hospitalized Myocardial Infarction. Circulation. 2010; 121:863-869. [PubMed: 20142444] 
5. Yeh RW, Sidney S, Chandra M, Sorel M, Selby JV, Go AS. Population trends in the incidence and outcomes of acute myocardial infarction. N Engl J Med. 2010; 362(23):2155-2165. [PubMed: 20558366]

6. Manhapra A, Canto JG, Vaccarino V, Parsons L, Kiefe CI, Barron HV, Rogers WJ, Weaver WD, Borzak S. The relation of age and race with hospital death after acute myocardial infarction. Am Heart J. 2004 Jul; 148(1):92-98. [PubMed: 15215797]

7. Vaccarino V, Parsons L, Every NR, Barron HV, Krumholz HM. National Registry Myocardial Infarction. Sex-based differences in early mortality after myocardial infarction. N Engl J Med. 1999; 341(4):217-225. [PubMed: 10413733]

8. Mann D, Reynolds K, Smith D, Muntner P. Trends in statin use and low-density lipoprotein cholesterol levels among US adults: Impact of the 2001 National Cholesterol Education Program guidelines. Ann Pharmacother. 2008; 42(9):1208-1215. [PubMed: 18648016]

9. Ford ES, Ajani UA, Croft JB, Critchley JA, Labarthe DR, Kottke TE, Giles WH, Capewell S. Explaining the decrease in US deaths from coronary disease, 1980-2000. N Engl J Med. 2007; 356(23):2388-2398. [PubMed: 17554120]

10. Barrett, M.; Coffey, R.; Levit, K. Population Denominator Data for Use with the HCUP Databases (Updated). HCUP Methods Series Report \# 2008-07. Rockville, MD: U.S. Agency for Healthcare Research and Quality; 2008.

11. Roger VL, Go AS, Lloyd-Jones DM, Adams RJ, Berry JD, Brown TM, Carnethon MR, Dai S, de Simone G, Ford ES, Fox CS, Fullerton HJ, Gillespie C, Greenlund KJ, Hailpern SM, Heit JA, Ho PM, Howard VJ, Kissela BM, Kittner SJ, Lackland DT, Lichtman JH, Lisabeth LD, Makuc DM, Marcus GM, Marelli A, Matchar DB, McDermott MM, Meigs JB, Moy CS, Mozaffarian D, Mussolino ME, Nichol G, Paynter NP, Rosamond WD, Sorlie PD, Stafford RS, Turan TN, Turner MB, Wong ND, Wylie-Rosett J. American Heart Association Statistics Committee and Stroke Statistics Subcommittee. Heart disease and stroke statistics--2011 update: a report from the American Heart Association. Circulation. 2011; 123(4):e18-e209. [PubMed: 21160056]

12. Centers for Disease Control and Prevention. Vitals signs: current cigarette smoking among adults aged > 18 years: United States, 2009. Morb Mortal Wkly Rep. 2009; (58):221-226.

13. Kontos MC, Fritz LM, Anderson FP, Tatum JL, Ornato JP, Jesse RL. Impact of the troponin standard on the prevalence of acute myocardial infarction. Am Heart J. 2003; 146(3):446-452. [PubMed: 12947361]

14. Spertus JA, Jones PG, Masoudi FA, Rumsfeld JS, Krumholz HM. Factors Associated With Racial Differences in Myocardial Infarction Outcomes. Ann Intern Med. 2009; 150:314-324. [PubMed: 19258559]

15. Mensah GA, Mokdad AH, Ford ES, Greenlund KJ, Croft JB. State of disparities in cardiovascular health in the United States. Circulation. 2005; 111(10):1233-1241. [PubMed: 15769763]

16. Jha AK, Varosy PD, Kanaya AM, Hunninghake DB, Hlatky MA, Waters DD, Furberg CD, Shlipak MG. Differences in medical care and disease outcomes among black and white women with heart disease. Circulation. 2003; 108(9):1089-1094. [PubMed: 12939228]

17. Kiyota Y, Schneeweiss S, Glynn RJ, Cannuscio CC, Avorn J, Solomon DH. Accuracy of Medicare claims-based diagnosis of acute myocardial infarction: Estimating positive predictive value on the basis of review of hospital records. Am Heart J. 2004; 148(1):99-104. [PubMed: 15215798] 


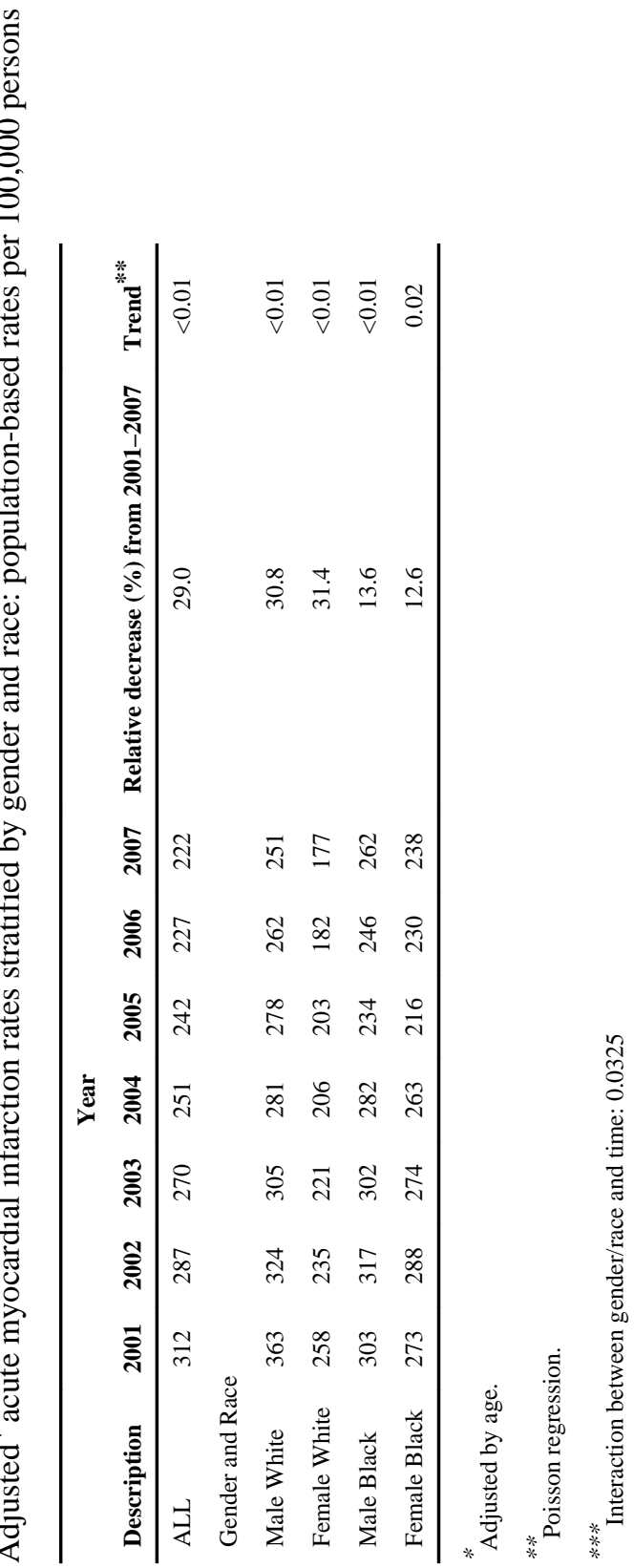

Am J Cardiol. Author manuscript; available in PMC 2013 June 01. 